\title{
Editoriali/Editorials
}

\section{Attitudes, values and beliefs of mental health workers}

\author{
LORENZO BURTI and LOREN R. MOSHER
}

\section{INTRODUCTION}

In the 14 years since the appearance of "Community Mental Health" (Mosher \& Burti, 1989) there has continued a trend, especially among psychiatrists, to denigrate the value of relationships in mental health treatment. Since psychiatrists are usually at least nominally "in charge" of ongoing treatment this devaluation of the importance of relationships affects the attitudes of other mental health workers as well. When psychodynamic and psychoanalytic thinking dominated the training of mental health professional's relationships were viewed as critical. A great deal of time was spent transmitting the howto of relating and in reviewing the role of the relationship in the ongoing therapeutic process.

At least from the American perspective this is no longer the case. In fact, with the expanding specialisation of psychiatry it is becoming more and more difficult to match technological specialisation and organisational efficiency with a human orientation in the therapeutic relationship. This major change in attitude, from a humanistic/interpersonal one to a scientific/technical orientation, that began in the mid-1970's, is even more prevalent today. This shift in attitude is, we posit, the result of the field of mental health and, more specifically, psychiatry's need, to be "scientific" and hence accepted

Address for correspondence: Professor L. Burti, Department of Medicine and Public Health, Section of Psychiatry, University of Verona, Policlinico G. B. Rossi, Piazzale L. A. Scuro 10, 37134 Verona, Italy.

Fax: +39-045-500873

E-mail: lorenzo.burti@univr.it

Declaration of Interest: none. by the rest of medicine. Psychological distress, emotional upset, and disturbed and disturbing behaviors have come to be viewed as "brain diseases". The unspoken, but clearly present implication is that such diseases are not amenable to interpersonal, i.e. psychosocial, interventions. The all too common phrase used is "you can't talk to disease". So psychiatric training is focused on understanding neurochemistry and how and when to use various medications. Of course, lip service is always given to the value of psychosocial treatment. What has resulted is the deskilling of psychiatrists who no longer understand how to use the relationship in their work with patients. It has also led to demoralization among those mental health workers whose only real therapeutic tool is relational. They have become enlightened baby sitters while the medications work their putative wonders. This new set of attitudes is really very destructive for patients and programs with a rehabilitation and recovery focus. Such programs are constantly having to deal with people who have been told by powerful persons, i.e. doctors, that they have life-long illnesses (like diabetes) with little hope of recovery but ones that can be kept in check or ameliorated by medication. These beliefs lend themselves to authoritarian, demeaning, dependency inducing, impersonal, distant and dehumanizing relationships. The context is one of utter hopelessness. Concepts of recovery and rehabilitation are difficult to put into practice in this context.

What is most perplexing about this "new" medical/scientific view of the mental health world is that the presently available scientific evidence does not support it! No specific "brain disease" for any of the major psychiatric diagnostic categories has been identified. Nevertheless, today's psychopharmacologic and biomedical model dominance contributes to at least psychiatrist's attitudes toward clients as a conglomeration of diseased neuro- 
transmitters with the consequence of a common disinterest in the use of relationships as clinically important.

\section{PROGRAMS}

Before embarking on more detailed recommendations several facts are noteworthy: Despite today's medicalization, high quality mental health programs are labor intensive, relationship based and non-technical. Their elements should include: Prompt, accessible, client centered, recovery oriented, quality mental health and rehabilitation services; decent affordable housing; and appropriate, ongoing self-help focused social supports. Systems that contain an array of these services have been shown to be both cost effective and voluntarily used because they address basic human needs. Overall program goals are to maximize self-determination, provide relationships that are empowering, minimize stigmatization and discrimination, and facilitate the development of meaningful social roles for its clientele. For mental health workers to be able to work effectively the context must provide role models for, be imbued with, transmit and consistently support a special set of relationally oriented set of attitudes, beliefs and values. As noted above an atmosphere of "chronic" "hopeless" disease makes it impossible to put these principles into practice. These are (modified from Mosher \& Burti, 1989, 1994, 2002).

\section{ATTITUDES AND VALUES}

- Do no harm.

- Treat, and expect to be treated, with dignity and respect.

- Be hopeful and convey positive expectations.

- Be flexible and responsive.

- In general the "user" (client, patient) knows best. We each know more about ourselves than anyone else. This is often a vast untapped reservoir of useful information.

- Choice, the right to refuse, informed consent, and voluntarism are essential to program functioning. Without options, freedom of choice is illusory. Hence, involuntary treatment should be difficult to implement and used only in the direst of circumstances.

- Expression of strong feelings and development of potential are acceptable and expected of the clienteleand are not usually signs of "illness".

- Whenever possible, legitimate needs (e.g. housing, social, financial, etc.) should be filled.
- Risks are part of the territory; if you don't take chances nothing ever happens.

- Power differentials are inevitable so to prevent their being destructive they should be acknowledged and discussed.

\section{NON-SPECIFIC PSYCHOSOCIAL INTERVENTION FACTORS}

Because we are discussing attitudes that will help mental health workers be effective psychosocial change agents we believe it is important that factors common to successful change be understood and used to maximize personal and programmatic effectiveness.

First elaborated by Frank (1971), after an exhaustive review of studies of successful psychotherapy, these common factors are:

- A healing context.

- Development of a confiding relationship with a "helper".

- Collaborative understanding of a plausible causal explanation.

- Therapist personal characteristics generate positive expectations.

- Provision of success experiences.

\section{RELATIONAL PRINCIPLES}

(All help facilitate the development of relationships)

The usefulness of these non-specific therapeutic factors can be maximised if clinicians can also keep in mind certain relational styles in their day-today work with clients. Each relational principle will be paired with one or more of the non-specific factors. Note how the principles overlap with the attitudes and values explicated above.

1. Atheoretical Need to Understand (Plausible Causal Explanation): This is meant to encourage relationships that are open, non-judgemental, tolerant, and respectful. The clinician tries to understand what's going on with clients while avoiding categorizations.

2. Continuity of Relationships (Confiding Relationship): Unless a program is organised to allow and promote continuity, its implementation is difficult. Basically we propose that a team of three or more persons should be each client's primary therapeutic case manager/consultant wherever he/she is in the program.

3. Response Flexibility (Confiding Relationship, Success Experiences): Basically this principle is intended to 
keep workers constantly alert and responsive to changes in the overall situation, in clients' clinical statuses and in their needs. It will be difficult to implement in hierarchical organisations, which tend to impair clinicians' abilities to respond to shifting situational demands, or in programs operating from a single theoretical perspective.

4. Being With, "Standing by Attentively," "Letting Be" (Confiding Relationship): This relational style will allow open nonjudgmental acceptance, empathic understanding, support, reassurance, validation, and containment without being overintrusive, overtalkative, or demanding, and without projecting unrealistic expectations. Its hallmark is a positive, attentive presence without an expectation of doing something to the client. It should be the major modus operandi with very fragmented, disorganised clients.

5. Concrete Problem Focus (Success Experiences. Plausible Causal Explanation): For many clients it will be difficult to begin addressing psychological and interpersonal issues until pressing financial, work, and housing issues are dealt with. It is not easy to approach a relational problem with someone who doesn't know how he's going to feed him/herself. Hence, the first priority in a problem-solving and relationship-building strategy should be practical, day-to-day issues. This approach will also provide opportunities for immediate successes that are remoralizing and self-esteem and confidence building. It will build a relationship because real needs are being acknowledged, addressed seriously and, we hope, filled. There's nothing like gratitude to help build a relationship! This can be viewed as a "doing with" relational mode.

6. Consultation (Healing Context, Positive Expectations): The advantages of consultative relationships over two-party relationships are: (1) They tend to be focused on a return to functioning rather than a "cure"; (2) they are usually collaborative, self-help, and peer-oriented relationships rather than those in which the therapist sets the agenda and is "one up" on the client; (3) the principal focus is on the development of competence rather than on psychopathology and dysfunction.

7. Partnership (Success Experiences): It is good practice for staff to approach clients in a humble frame of mind. Every encounter should be viewed as potentially therapeutic. However it is difficult to create truly equal relationships. There will be status and power differences. They cannot be avoided. To minimise their potentially deleterious effects, they should be recognised, acknowledged, and discussed. The aim is to develop relationships that can evolve into more or less reciprocal (friend-like) ones over time. Proper use of this partnership orientation preserves client power, acknowledges the temporary nature of the need for help, and minimises the staff's role as "experts." Staff can be usefully authoritative (e.g., by sharing what they've learned from their relevant life experiences) without being authoritarian. Temporary parent-like relationships are also fine, so long as they don't outlive their usefulness and become permanently established as non-reciprocal, dependent ones.

8. Expectation of self-help (Healing Context): Clients should be encouraged to evolve potential problem-solving strategies themselves and be helped, as necessary, to try them. They can be their own experts. Staff should intervene only when a strategy that is clearly destructive is about to be tried. Self-help is really mutual help.

By displaying these relational modes in a clear and consistent manner, staff is more likely to become persons clients will seek to imitate and identify with over time-a key change process.

\section{CLINICAL PRINCIPLES}

There are three "umbrella" processes that must always be kept in mind by mental health program staff: (1) contextualization; (2) preservation and enhancement of personal power and control; and (3) normalisation. They also express a set of attitudes, values and beliefs.

1. Contextualization: By this we mean keeping clients in as close contact with their usual surroundings, both geographic and interpersonal, as possible. We recommend that staff approach users so that they define the nature of the problem; then, staff can elucidate the environmental events temporally related to it, focus on clients' notions about problem solutions, and ask them what resources the team can help mobilise to deal with the problems. Validation of clients' subjective experience by the use of active empathy will also help keep them in their context. The staff's job in this regard is to negotiate, over time, a compromise between the objective historical societal reality and the reality of clients' subjective experience. These two versions of reality need to be reconnected, since their disconnection has been part of the problem development. Contextualization is further facilitated by focusing on various aspects of clients' networkstheir family and friends and the relevant professional network.

2. Preservation and enhancement of personal power and control: An all too frequent attitude found among mental health staff is their presumption that they know what is best for the users, especially if they are very disturbed and disturbing. This deprives clients of their 
power and undermines their sense of being in control of their lives even though this is often a major feature of their problem. Staff can enhance personal power by providing information, helping to identify options, role playing and practising scenarios, exercising advocacy, and most particularly, spending a great deal of time and energy keeping the client engaged in the entire helping process. The primary modus operandi in community mental health programs should be to serve as facilitators for clients' identification, definition, development, and expansion of their personal cognitive and emotional resources. The ultimate goal is that of maximal self-help. Hence, relationships evolved within a program will need to be collaborative, interdependent, reciprocal, and facilitative. They will usually be characterised by a "being with," rather than a more activist "doing to," interaction process. Adherence to this kind of process will maintain and enhance client power and diminish splitting and blaming. The staff should see their roles more as consultants (a less powerful and less activist position) than therapists (a term that implies "doing"). Activism per se is not the problem; in fact, we firmly believe in the importance of advocacy, a very activist function. However, the activism of "therapy" can be distorted in a way that aligns it with therapist, rather than client, goals or with adaptation to the status quo. Helpers must always keep a minimalist philosophy in mind. The less they do the better. They should always be looking for ways to involve and support use of available non mental-health network resources.

3. Normalisation (usualization) (Wolfensberger, 1970): This principle overlaps to some extent with contextualization. However, they are distinguishable by time and reference frames: the process of contextualization is primarily an individualised longitudinal, historical point of view while normalization is principally a group crosssectional, societal, or cultural norm perspective. That is, we mean there will always be times when clients are not able, by themselves, to generate the options they may need to solve a particular problem. It falls to the staff to help them develop options. In doing so, staff should think first of options that are most nearly normal.

\section{A PROGRAM EXAMPLE: SOUTH-VERONA}

Principles of intervention: at the South-Verona Community Psychiatric Service (Tansella et al., 1998) workers strongly believe in the importance of a stable and trusty therapeutic relationship. Therefore, the service is organized in order to foster continuity of care: communi- ty teams follow their patients wherever they are treated at that specific time, whether they are in outpatient, day or inpatient care. A key worker, usually a resident or a nurse, is in charge of a given patient and is backed by a core team including one or two more workers to assure continuity of care in spite of shifts, vacations, sick leaves and turnover. This is especially true in the case of longterm patients, who are closely followed-up. In fact, either they attend the day center, or are regularly seen by their key worker, usually on a weekly basis. Patients are invited to contact the service, especially the community mental health center, in person or on the phone, whenever they wish, without the need for an appointment or a referral. When a patient arrives, he probably finds one of his personal workers, somebody he already knows and confides in. Strong, often affectionate relationships between staff and patients may ensue over time, that help treatment, especially in the case of a relapse. When excitement and behavior disorganization are present, personal trust really makes the difference: the service is fond of its low number of involuntary commitments, no more than a dozen a year, about five per cent of all hospital admissions.

As to the use of medications, staff is in favor of using drugs with the minimum of side effects at the lowest effective dosage. The prescription of depot neuroleptics is conscientiously pondered. At present, the SouthVerona Psychiatric Service participates in a multicentric European study on the effectiveness of a psychological intervention to improve adherence to treatment by emphasizing patients' personal choice and responsibility.

The service is committed to meet all psychiatric needs of the adult population of the catchment-area, the southern outskirts of Verona and three nearby country towns (a relatively small, suburban district with an overall population of about 100,000 inhabitants). This implies the responsibility for the care of all cases, including the most severe ones, without the backup of the psychiatric hospital, which was ruled out by the Italian psychiatric reform a quarter of a century ago, in 1978. Based on the recognition that crisis teams are able to reduce hospitalization (Burns et al., 2001), crisis interventions at patient's home are used when appropriate. They usually involve a couple of workers or a team of three, if needed, including a psychiatrist. Home visits are also offered on a regular basis for follow-up and to provide support to the family. However, given the good accessibility of the service because of the short distances involved, patients can easily attend out-patient and day care and are encouraged to do so. Relatives are invited to participate in a two-year long support and education program, with sessions twice

Epidemiologia e Psichiatria Sociale, 12, 4, 2003 
a month. At the end of the program they are advised to continue to meet on their own, under the lead of a senior family-member who runs an ongoing self-help group.

Daily and weekly team meetings are held for reciprocal supervision on casework; all important decisions regarding patients are taken within the team, after extensive discussion where all members have a say, including junior staff and residents in training. The influence of hierarchy is intentionally reduced and authority, based on experience rather than position, stressed. Residents in training, who have higher status but less experience, work in close association with the more experienced nurses, with positive effects on learning and morale. A brief, case-centered, orientation meeting involving all the staff of the service initiates every working day: the doctor on duty reports on the events of his/her shift. Then individual teams meet separately, to plan the activities of the day.

Residents and nurses are granted responsibility and freedom to make decisions. Permanent-staff professionals offer supervision and backup when needed, rather than give orders. Workers are never left alone; they are empowered and can always rely on supervision. This greatly contributes to the prevention of burnout, which is rarely seen in South Verona.

To increase consumer participation and facilitate patients' empowerment, the service sponsored and supported the development of a psychiatric self-help group. The group now collaborates with the service and a nonprofit private organization to run a very successful psycho-social center that effectively complements the activities of traditional services in areas like housing, work and social activities.

\section{CONCLUSION}

Attention to the types of attitudes, values and beliefs that facilitate positive therapeutic relationships between mental health staff and their clientele is critical for successful programs. We believe that, given the current "medicalization" zeitgeist in mental health, a relational focus is imperilled. It is our hope that what we've outlined here will help guide staff's efforts to relate to the whole person-and that this relationship will be viewed as crucial for successful client recovery and rehabilitation.

\section{REFERENCES}

Burns T., Knapp M., Catty J., Healey A., Henderson J., Watt H. \& Wright C. (2001). Home treatment for mental health problems: a systematic review. Health Technology Assessment 5, 1-139.

Frank J.D. (1971). Eleventh Emil A. Gutheil memorial conference. Therapeutic factors in psychotherapy. American. Journal of Psychotherapy 25, 350-361.

Mosher L.R. \& Burti L. (1989). Community Mental Health: Principles and Practice. Norton: New York.

Mosher L.R. \& Burti L. (1994). Community Mental Health: A Practical Guide. Norton: New York.

Mosher L.R. \& Burti L. (2002). Psichiatria Territoriale. Centro Scientifico Editore: Torino.

Tansella M., Amaddeo F., Burti L., Garzotto N. \& Ruggeri M. (1998). Community-based mental health care in Verona, Italy. In Mental Health in Our Future Cities (ed. D. Goldberg and G. Thornicroft), pp. 239-262. Psychology Press: Hove (UK).

Wolfensberger W. (1970). The principle of normalization and its implications to psychiatric services. American Journal of Psychiatry 127, 291-297. 